\title{
DINÂMICA DO USO DO SOLO NA ILHA DE CARATATEUA, BELÉM, PARÁ
}

\author{
Adrian Loyan de Sá Bentes'; Alberto Bentes Brasil Neto1; Perseu da Costa Andrade2; Aline Nascimento \\ Braga $^{3}$; Victor da Cruz Peres'; Rodrigo Alan Teixeira Santos Júnior'; Mayra Jessica Baima Franco'; Ana Beatriz \\ Sousa Santos'.

\begin{abstract}
1'Instituto Federal de Educação, Ciência e Tecnologia do Pará. Óbidos, Pará, Brasil, adrianloyanbentes2@gmail.com, alberto.neto@ifpa.edu.br, victor.peres@ifpa.edu.br, rodrigoalan0698@gmail.com, mayrajessica50@gmail.com, sanabeatriz478@gmail.com

3Universidade Federal do Pará, Belém, Pará, Brasil, alinensbraga@gmail.com
\end{abstract} \\ ¿Universidade Federal Rural da Amazônia, Belém, Pará, Brasil, perseuandrade@hotmail.com
}

RESUMO: O presente trabalho teve como objetivo avaliar a dinâmica do uso do solo, entre os anos de 1984 e 2015, por meio do processamento digital de imagens, e aplicação de questionários para avaliar a relação do uso do solo com a qualidade de vida dos moradores da ilha de Caratateua, Belém, Pará. Foram utilizadas imagens do satélite LANDSAT-5, bandas 3, 4 e 5, dos anos 1984, 1999, 2008 e 2015, as quais foram submetidas à classificação supervisionada por máxima verossimilhança. Posteriormente, obteve-se mapas com classes de uso do solo, sendo mais expressivas a Vegetação Densa, Capoeira (Floresta Secundária), Solo Exposto e Área Urbana. Foram aplicados 50 questionários com a pergunta: Quais os principais problemas que interferem na qualidade de vida da população da ilha de Caratateua? O período entre os anos de 1984 a 1989 foi o de maior crescimento urbano na ilha. A falha na gestão ambiental e urbanística, associados ao processo de crescimento desordenado, que, aliado a outros fatores, resultou no aumento desordenado de áreas urbanas e vem gerando impactos sociais, em especial com o aumento da violência e da carência de saneamento básico, e ambientais, por meio do uso indiscriminado dos recursos naturais e do solo.

PALAVRAS-CHAVE: Monitoramento ambiental, Processamento de imagens digitais, Sensoriamento remoto.

\section{DYNAMICS OF SOIL USE AND ITS RELATION WITH THE QUALITY OF LIFE OF THE INHABITANTS OF THE ISLAND OF CARATATEUA, BELÉM, PARÁ}

ABSTRACT: The objective of this study was to evaluate the dynamics of soil use between 1984 and 2015 through digital image processing and questionnaires to evaluate the relationship between soil use and the quality of life of the (LANDSAT-5), bands 3, 4 and 5, from 1984, 1999, 2008 and 2015, which were submitted to supervised classification by maximum likelihood. Subsequently, maps with classes of land use were obtained, being more expressive the Dense Vegetation, Capoeira (Secondary Forest), Exposed Ground and Urban Area. Fifty questionnaires were applied with the question: What are the main problems that interfere in the quality of life of the population of the island of Caratateua? The period between the years 1984 to 1989 was the one of greater urban growth in the 
island. The lack of environmental and urban management associated with the disorderly growth process, which, combined with other factors, has resulted in the disorderly increase of urban areas and has generated social impacts, especially with increasing violence and lack of basic sanitation, and through the indiscriminate use of natural resources and soil.

KEYWORDS: Environmental monitoring, Processing of digital images, Remote sensing.

\section{DINÁMICA DEL USO DEL SUELO Y SU RELACIÓN CON LA CALIDAD DE VIDA DE LOS HABITANTES DE LA ISLA DE CARATATEUA, BELÉM, PARÁ}

RESUMEN: El presente trabajo tuvo como objetivo evaluar la dinámica del uso del suelo, entre los años 1984 y 2015, por medio del procesamiento digital de imágenes, y aplicación de cuestionarios para evaluar la relación del uso del suelo con la calidad de vida de los habitantes de los años 1984, 1999, 2008 y 2015, las cuales fueron sometidas a la clasificación supervisada por máxima verosimilitud. Posteriormente, se obtuvieron mapas con clases de uso del suelo, siendo más expresivas la Vegetación Densa, Capoeira (Bosque Secundaria), Solo Exposto y Área Urbana. Se aplicaron 50 cuestionarios con la pregunta: ¿Cuáles son los principales problemas que interfieren en la calidad de vida de la población de la isla de Caratateua? El período entre los años 1984 a 1989 fue el de mayor crecimiento urbano en la isla. La falla en la gestión ambiental y urbanística, asociados al proceso de crecimiento desordenado, que, aliado a otros factores, resultó en el aumento desordenado de áreas urbanas y viene generando impactos sociales, en especial con el aumento de la violencia y la carencia de saneamiento básico, y ambientales, a través del uso indiscriminado de los recursos naturales y del suelo.

PALABRAS CLAVE: Detección remota, Monitoreo ambiental, Procesamiento de imágenes digitales.

A crescente pressão antrópica sobre os diversos ecossistemas tem gerado impactos sobre o meio ambiente, bem como tem influenciado questões sociais, econômicas e culturais (GOUVEIA et al., 2013; SANTOS et al., 2015). Tais impactos são ocasionados pela falha ou ausência de planos de gestão ambiental, atingindo diretamente o meio ambiente por meio da expansão urbana desordenada, problemas de saneamento e redução da qualidade de vida da população.

Na Amazônia, o processo de ocupação antrópica geralmente esteve e está associado a geração de graves problemas ambientais. Neste contexto, a ilha de Caratateua, conhecida popularmente como ilha de Outeiro, distrito do 
município de Belém, Estado do Pará, é um

exemplo da ocupação desordenada e que atualmente tem sofrido com problemas ambientais e sociais.

Dessa forma, estudos que visam avaliar a dinâmica das alterações do uso do solo são fundamentais para conhecer o nível de alteração dos ecossistemas e planejar ações que visem minimizar impactos ambientais e sociais (NEVES et al., 2014; GRAÇA et al., 2015; SANTOS et al., 2017). Neste sentido, a utilização de técnicas de sensoriamento remoto tem sido fundamental para estes tipos de estudo por possibilitar: a realização de análises de alta precisão com baixo custo (TRABAQUINI et al., 2011); fazer monitoramentos através de comparações temporais (FORMIGONI et al., 2011) e podendo ser efetuada sem a necessidade de ir em campo (BRASIL NETO et al., 2014).

De acordo com GOMES et al. (2011), muitos estudos envolvendo a análise da dinâmica da vegetação e uso do solo têm sido possíveis por meio da adoção de técnicas de sensoriamento remoto.
Neste contexto, o presente trabalho teve como objetivo avaliar a dinâmica do uso do solo entre os anos de 1984 e 2015, por meio do processamento digital de imagens, análise de mapas, publicações e aplicação de questionários, para retratar a ocupação e uso do solo na ilha de Caratateua/PA, visando identificar e avaliar a evolução dos processos que promovem degradação da llha e oferecer subsídios para orientar medidas que visam minimizar os impactos ambientais e melhoria na qualidade de vida dos moradores locais.

A Ilha de Caratateua, ou llha de Outeiro, como é popularmente conhecida, é um distrito pertencente ao município de Belém-PA, situada entre as latitudes $1^{\circ} 12^{\prime}$ e $1^{\circ} 17^{\prime} \mathrm{S}$ e entre as longitudes de 48025' e 48029' W GR, compondo a região nordeste do Estado do Pará (Figura 1).

O acesso a ilha se dá tanto de forma fluvial, como terrestre, através da ponte governador Enéas Pinheiro (com 380 metros de extensão), distante $25 \mathrm{~km}$ do centro da cidade. A ponte do Outeiro foi inaugurada no dia 26 de outubro de 1986. 
Figura 1. Mapa de localização geográfica de Caratateua, distrito de Belém/PA.

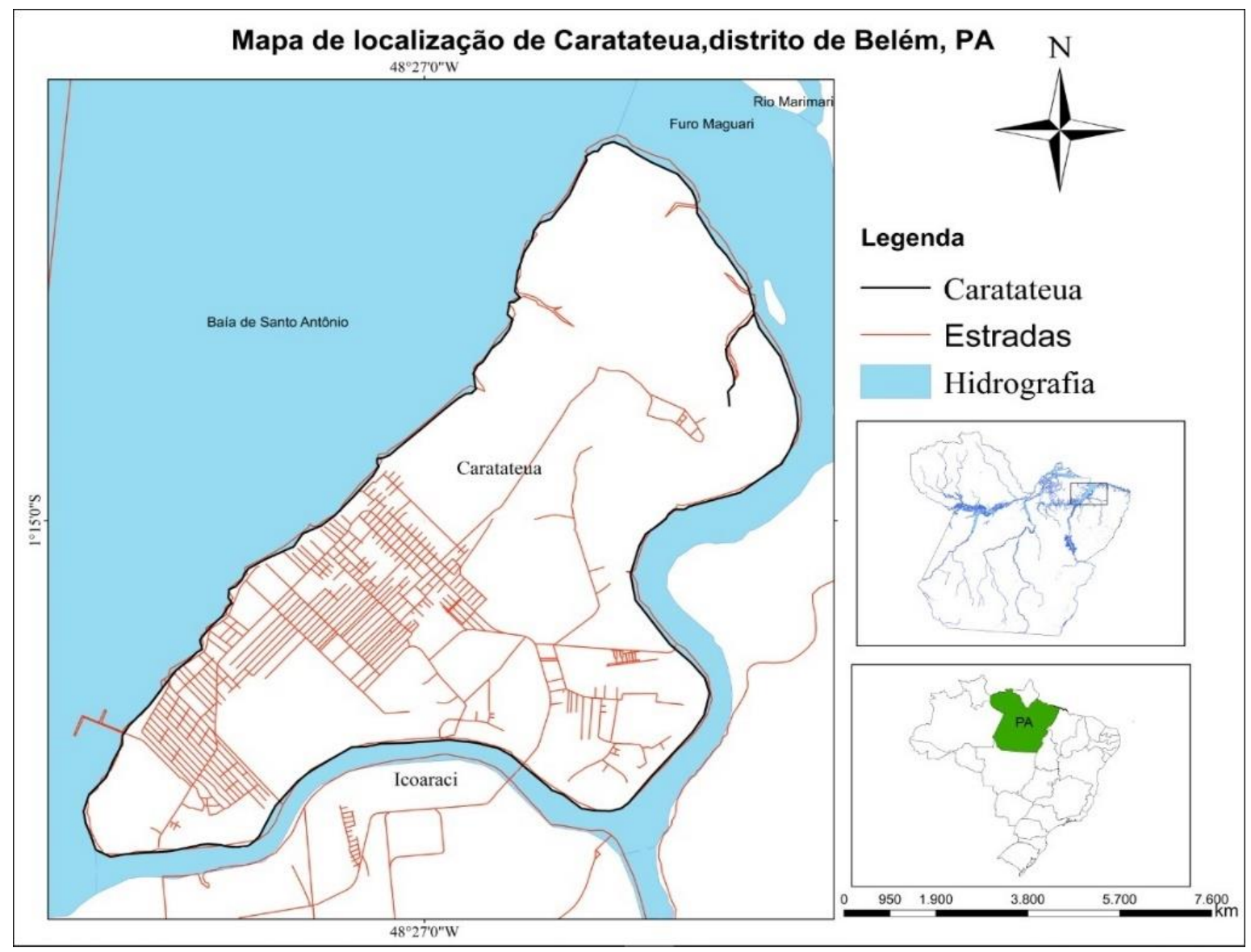

Para o levantamento dos dados referentes a cobertura vegetal, uso e ocupação do solo da llha de Caratateua, foram utilizadas imagens do satélite LANDSAT-5 da órbita/ponto 224/62, bandas 3, 4 e 5, do sensor TM (Thematic Mapper) dos anos 1984, 1999, 2008 e 2015, disponíveis de forma gratuita no site do Instituto Nacional de Pesquisas Espaciais - INPE. A imagem do ano de 2015 foi obtida do site EARTH EXPLORER, sendo correspondente do satélite
LANDSAT 8, sensor Operacional Terra Imager (OLI), órbita/ponto 224/62, datada do dia 07/09/2015, com resolução espacial de 30m, composição Colorida RGB das bandas 6-5-4, correspondente à composição Landsat-5 RGB 5-4-3. Após obter as imagens, aplicou-se o préprocessamento das mesmas, realizando recorte, correção radiométrica e realizando o georreferenciamento.

O processamento digital das imagens foi realizado por meio da classificação 
"pixel a pixel" utilizando apenas a informação espectral de cada pixel para localizar regiões homogêneas, onde se faz o processo de extração de informação em imagens para reconhecer padrões e objetos homogêneos, sendo utilizados em Sensoriamento Remoto para mapear áreas da superfície terrestre que correspondem aos temas de interesse, que nesse caso foram: Vegetação densa (Floresta Ombrófila Densa de Terra Firme e de Várzea e fragmentos florestais), Vegetação Secundária (processo de sucessão florestal secundária), Vegetação rasteira (cultivo agrícola, vegetação aquática e áreas de pastagens), Solo exposto (áreas em fase de preparo para implantação agropecuária e áreas degradadas), Área Urbana (instalações residenciais e industriais e áreas com pavimentação asfáltica) e Outros (corpos d'água e, em menor proporção, pixels não classificados). Todo o processo foi supervisionado pelo algoritmo da Máxima Verossimilhança.

Os softwares utilizados no prétratamento e tratamento das imagens orbitais da pesquisa foram: Environment For Visualizing Images - (Envi) versão 5.2 e ArcGis 10.3.1 com o tratamento e a classificação das imagens dos diferentes anos, foi realizada a pós-classificação das mesmas, nas quais foram computadas a área ocupada por cada classe prédeterminada. $\mathrm{O}$ estudo foi desenvolvido no Laboratório de Geoprocessamento, Análise Espacial e Monitoramento por Satélite-LAGAM da Universidade Federal Rural da Amazônia e no Laboratório de Estudos Ambientais-LABEAM do Instituto Federal do Pará, Campus Óbidos.

Procedeu-se também pesquisa de campo com 50 moradores da ilha, através de questionário, com uma pergunta: Quais os principais problemas que interferem na qualidade de vida da população da ilha de Caratateua? Posteriormente, as informações descritas foram sistematizadas e submetidas à técnica estatística de distribuição de frequências.

Os valores referentes à quantificação das classes: Vegetação Densa, Vegetação Secundária, Vegetação Rasteira, Solo Exposto, Rios, Área Urbana e outras (corpos d'água e, em menor proporção, pixels não classificados), na llha de 
Caratateua, estão apresentados na Tabela 1.

Os mapas de classificação para as classes temáticas: Vegetação rasteira, capoeira e densa; área urbana; solo exposto; rios nos anos de 1984, 1999, 2008 e 2015 são apresentados na Figura 2.

Tabela 1. Distribuição das classes de cobertura vegetal e uso do solo na Ilha de Caratateua, Município Belém/PA nos anos de 1984, 1999, 2008 e 2015.

\begin{tabular}{ccccccccc}
\hline \multirow{2}{*}{ Descrição } & \multicolumn{7}{c}{ Área em km² $^{2}$} \\
\cline { 2 - 9 } & 1984 & $\%$ & 1999 & $\%$ & 2008 & $\%$ & 2015 & $\%$ \\
\hline Vegetação Densa & 6,01 & 18,69 & 5,08 & 15,80 & 5,42 & 16,86 & 4,38 & 13,62 \\
Veg. Secundária & 16,42 & 51,07 & 14,97 & 46,56 & 12,3 & 38,26 & 12,23 & 38,04 \\
Vegetação Rasteira & 6,51 & 20,25 & 3,55 & 11,04 & 4,15 & 12,91 & 4,65 & 14,46 \\
Solo Exposto & 1,34 & 4,17 & 0,25 & 0,78 & 0,9 & 2,80 & 0,65 & 2,02 \\
Área Urbana & 1,18 & 3,67 & 7,51 & 23,36 & 8,6 & 26,75 & 8,92 & 27,74 \\
Outros* & 0,69 & 2,15 & 0,79 & 2,46 & 0,78 & 2,43 & 1,32 & 4,11 \\
\hline Total & 32,15 & 100 & 32,15 & 100 & 32,15 & 100 & 32,15 & 100 \\
\hline
\end{tabular}

*Nuvens e pixels não identificados.

Figura 2. Mapa da dinâmica de paisagem, uso e evolução da ocupação do solo na ilha de Caratateua/PA no ano de 1984, 1999, 2008 e 2015.

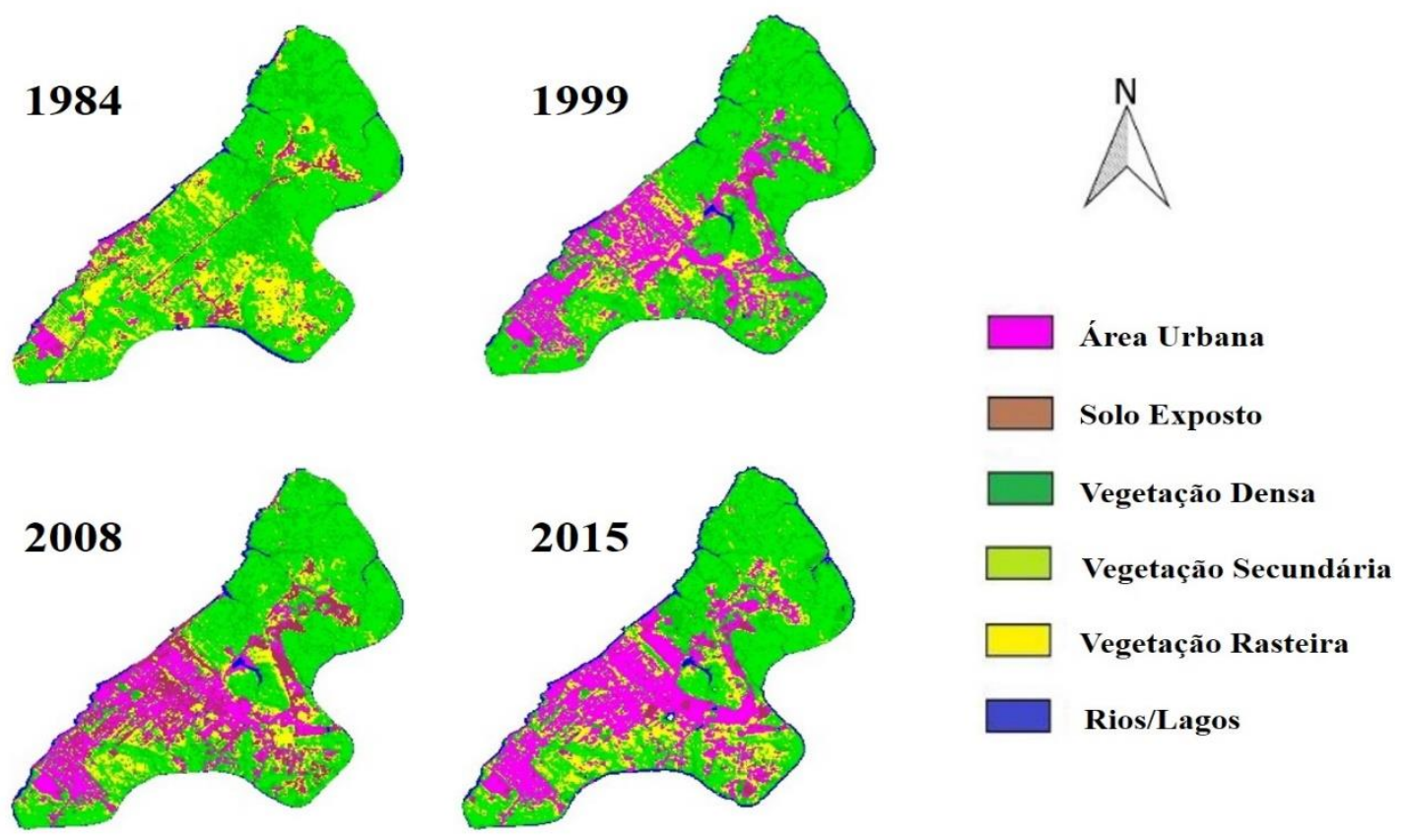


Ao analisar a Figura 2, observa-se que a área ocupada por núcleos urbanos somava apenas 3,7\% da área total da ilha de Caratateua no ano de 1984. De acordo com Barbosa et al. (2012), até o final do século XIX, havia o predomínio de atividades como o extrativismo e produção de subsistência nas ilhas de Belém.

O maior crescimento urbano ocorreu no período entre os anos de 1984 e 1999. Em 1984, 3,6\% da área total da ilha era ocupada por área urbana e num período de 15 anos, esta classe já totalizava 23,4\%. A explicação para o crescimento urbano foi a inauguração da Ponte Enéas Pinheiro, em 1986, que, juntamente com a construção da avenida Augusto Montenegro, facilitou o acesso a ilha (Santos et al., 2014). No ano de 2015, 28\% da ilha era ocupada por núcleos urbanos.

No ano de 1988, a população da ilha era de 7.096 habitantes; apenas dois anos mais tarde, essa população cresceu 125\%, dando um salto para 15.976 habitantes (ASSUNÇÃO, 2005). Esta autora aponta os seguintes motivos como causa desse crescimento exponencial da população da ilha: (1) construção da Ponte Enéias
Martins; (2) migração da população residente nas periferias de Belém, especialmente de áreas alagáveis, vulgarmente conhecida como baixadas e (3) especulação imobiliária.

Este crescimento desordenado está associado na falta de uma gestão ambiental e urbanística na ilha, resultando no aumento desordenado na área urbana e gerando impactos ambientais por meio do uso indiscriminado dos recursos naturais e do solo. De acordo com RUBIO (2001), entre os anos de 1984 e 2001 houve desmatamento acentuado onde se encontra os bairros de São João do Outeiro, Brasília e Água Boa, bem como na região oeste da ilha, a qual possuía identidade rural. Ainda segundo este autor, em termos de vegetação densa, área mais preservada da ilha localizava-se ao norte.

De acordo com BARBOSA (2012), a expansão urbana na ilha de Caratateua ocorreu em locais anteriormente utilizados para extração mineração e atividades agrícolas. Ainda segundo este autor, não houve planejamento para ocupação destes locais, ocasionando problemas sociais e ambientais. 
Por sua vez, as classes vegetação densa, vegetação secundária e vegetação rasteira sofreram redução entre os anos de 1984 e 1999, que pode ser explicado pelo grande crescimento urbano ocorrido neste período. Entre 1984 e 2015 houve uma redução pequena da vegetação densa, de 19\% para 14\%. Tal fato está ligado a dois fatores: o primeiro é que a vegetação secundária (capoeira) sofreu um processo conhecido como sucessão florestal/ecológica, tornando-se vegetação densa, visto que as imagens foram coletadas em um intervalo de trinta e um anos; o segundo fator foi a facilidade para implantação de moradias e outras ações antrópicas em áreas de vegetação rasteira e de capoeira, uma vez que a dificuldade para realizar a atividade de supressão florestal em áreas de vegetação densa é maior. Por conseguinte, percebese uma perda maior quando se trata de vegetação rasteira e secundária.

No ano de 1994, a área ocupada por vegetação Secundária ocupava 51\% e no ano de 2015, 38\%. Estes resultados indicam que grande parte das áreas ocupadas por núcleos urbanos foram oriundas da supressão de vegetação secundária neste período.

No ano de 2015, uma das classes com maior destaque é a área urbana. Os resultados dos questionários aplicados aos moradores indicam que os principais problemas que interferem na qualidade de vida da população da ilha de Caratateua são: (1) Falta de segurança, relatado por $100 \%$ dos entrevistados e (2) Deficiência no saneamento básico, citado por $75 \%$ dos entrevistados.

Tais resultados estão associados ao processo histórico de ocupação desordenada e de geração de problemas sociais e ambientais, necessitando de medidas mitigadoras, tais como: (1) Sensibilização da comunidade e órgãos oficiais e não-oficiais preservacionistas; (2) Reflorestamento das áreas degradadas; (3) Implantação de obras de infraestrutura, saneamento básico e coleta de lixo em toda a ilha; (4) Implantação de mais centros comunitários e escolas, para integrar, sensibilizar e esclarecer a comunidade e (5) alocação de mais postos de observação da polícia militar, para contribuir para o aumento da segurança na ilha. 
O período entre os anos de 1984 a 1989

foi o de maior crescimento urbano na ilha de Caracateua. A falha na gestão ambiental e urbanística, associados ao processo de crescimento desordenado, que, aliado a outros fatores, resultou no aumento desordenado de áreas urbanas e vem gerando impactos sociais, em especial com o aumento da violência e da carência de saneamento básico, e ambientais, por meio do uso indiscriminado dos recursos naturais e do solo.

\section{REFERÊNCIAS}

ASSUNÇÃO, M. F. A política municipal de educação nos anos de 1990 na ilha de Caratateua/Belém-Pará. Dissertação (Mestrado em Educação) - Universidade Federal do Pará, Belém, 2005.

BARBOSA, E. J.da S.; SANTO, C. M. do E.; SANTOS, V. C.; BRAGA, R. da C.; MORAES, S. F. Percursos geográficos: pesquisa e extensão no distrito de Outeiro, Belém Pará (2008 - 2011): produção e apropriação da natureza na ilha de Caratateua, Belém (PA). 1. ed. - Belém: GAPTA/UFPA, 2012.

BRASIL NETO, A. B.; PAUMGARTTEN, A. E. A.; BRAGA, A. N.; MACIEL, M. N. M.; SILVA, P. T. E. Dinâmica da cobertura vegetal e uso do solo no entorno do parque estadual do Utinga (PEUt), Belém-PA.
Enciclopédia Biosfera, v.10, p. 2120-2128, 2014.

FORMIGONI, M. H.; XAVIER, A. C.; LIMA, J. S. S. Análise temporal da vegetação na região do Nordeste através de dados EVI do MODIS. Ciência Florestal, v. 21, n. 1, p. 1-8, 2011.

GOMES, D. D. M.; MENDES, L. M. S.; MEDEIROS, C. N.; VERÍSSIMO, C. U. V. Análise multitemporal do processo de degradação da vegetação da bacia hidrográfica do Rio Jaibaras no Estado do Ceará. Geografia, Ensino e Pesquisa, v. 15, n. 2, p. 41-61, 2011.

GOUVEIA, R. G. L.; GAVANIN, E. A. S.; NEVES, S. M. A. S. Aplicação do indíce de transformação antrópica na análise multitemporal da Bacia do Córrego do Bezerro Vermelho em Tangará da SerraMT. Revista Árvore, v.37, n.6, p.1045-1054, 2013.

GRAÇA, C. H.; PASSIG, F. H.; KELNIAR, A. R.; PIZA, M. A.; CARVALHO, K. Q.; ARANTES, E. J. Multitemporal analysis of estimated soil loss for the river Mourão watershed, Paraná - Brazil. Brazilian Journal of Biology, v. 75, n. 4, p. 120-130, 2015.

NEVES, C. E., SILVA, G. M. F. Dinâmica da paisagem em 10 Municípios do Cerrado Piauiense entre 1991, 2001 e 2010 através de técnicas de geoprocessamento. Revista Geonorte, v.10, n.4, p.41-46, 2014.

RUBIO, Maria Dolores Torres. Caratateua mostra tua cara - aspectos históricos e mudanças socioambientais: um estudo na ilha. Belém, 2001, 93f. Trabalho de Conclusão do Curso (Especialização em Educação Ambiental) - Núcleo de Meio 
Ambiente, Universidade Federal do Pará, Belém, 2001.

SANTOS, L. S. dos; SILVA JUNIOR, O. M. da; SOUSA, T. G. de. Análise da dinâmica da cobertura vegetal urbana na ilha de Caratateua, distrito de Belém-PA, utilizando índice de vegetação por diferença normalizada para os anos de 1984 e 2008. XXVI Congresso Brasileiro de Cartografia. Gramado, RS. 2014.

SANTOS, F. A.; AQUINO, C. M. S. Análise da dinâmica do índice de vegetação por diferença normalizada (NDVI), dos aspectos econômicos e suas relações com a desertificação/degradação ambiental em Castelo do Piauí, Piauí, Brasil. Revista Electrónica de Investigação e Desenvolvimento, n. 4, p. 2-17, 2015.

SANTOS, L. A. C.; BATISTA, A. C.; NEVES, C. O. M.; CARVALHO, E. V.; SANTOS, M. M.; GIONGO, M. Análise multitemporal do uso e cobertura da terra em nove municípios do Sul do Tocantins, utilizando imagens Landsat. Revista Agroambiente, v. 11, n. 2, p. 111-118, 2017.

TRABAQUINI, K.; MIGLIORANZA, E.; FRANÇA, $V_{\text {i; }}$ PEREIRA NETO, O. C. Caracterização de lavouras cafeeiras, utilizando técnicas de geoprocessamento e sensoriamento remoto, no Município de Umuarama - PR. Ciência e Agrotecnologia, v. 35, n. 1, p. 35-44, 2011. 